Document Number: SET 2014-0050

412TW-PA-14319
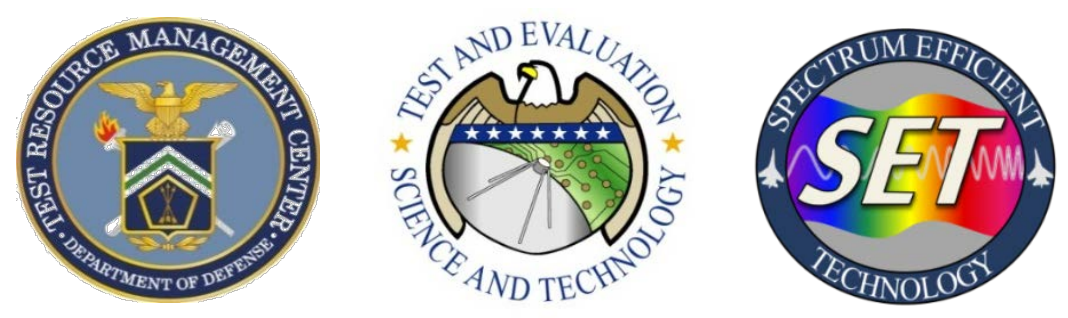

\title{
iNET Preamble Detector Performance in the Presence of Multipath Interference
}

\section{June 2014}

\section{Final Report}

Tom Young

SET Executing Agent

412 TENG/ENI

(661) 277-1071

Email: tommy.young.1@us.af.mil

Approved for public release; distribution is unlimited.

Controlling Office: 412 TENG/ENI, Edwards AFB, CA 93524

\section{Test Resource Management Center (TRMC) Test \& Evaluation/ Science \& Technology (T\&E/S\&T) Spectrum Efficient Technology (SET)}


Qualified requestors may obtain copies of this report from the Defense Technical Information Center, 8725 John J. Kingman Road, Suite 0944, Ft. Belvoir, VA 22060-6218. Department of Defense contractors must be established for DTIC services, or have a "need to know" certified by cognizant military agency for their project or contract.

When U.S. Government drawings, specifications, or any other data are used for any purpose other than a definitely related government procurement operation, the government thereby incurs no responsibility nor any obligation whatsoever; and the fact that the government may have formulated, furnished or in any way supplied the said drawings, specifications, or any other data is not to be regarded by implication or otherwise, as in any manner licensing the holder or any other person or corporation or conveying any rights or permission to manufacture, use or sell any patented invention that may in any way be related thereto.

\section{Do not return this copy; retain or destroy.}

\section{DESTRUCTION NOTICE}

For classified documents, follow the procedures in DoD 5220.22.M, National Industrial Security Manual (NISPOM), section 5-705, or DoD 5200.01 Vol. 1-4, DoD Information Security Program. For unclassified limited documents (ie., documents not approved for public release), destroy by any method that will prevent disclosure of contents or reconstruction of the document. 


\section{DISTRIBUTION LIST}

61 N. Wolfe Ave. Bldg 1632

Edwards, AFB, CA 93524

Attn: Michael Rice

459 Clyde Building

Brigham Young University

Provo, UT 84602

mdr@byu.edu

Attn: Erik Perrins

University Of Kansas Center For Research

2385 Irving Hill RD

Lawrence KS 66045-7563

esp@ku.edu

Andrew McMurdie

Provo, UT 84602

amcmurdie@gmail.com

Edwards AFB Technical Research Libaray

.

307 East Popson Ave, Bldg 1400

Edwards AFB CA 93524

\section{$\underline{\text { Offsite Distribution }}$}

Defense Technical Information Center

8725 John J Kingman Road, Suite 0944

Ft Belvoir, VA 22060-6218

U.S. ARMY PEO STRI Acquisition Center

Attn: Kaitlin F. Lockett

12350 Research Parkway

Orlando, FL 32826 


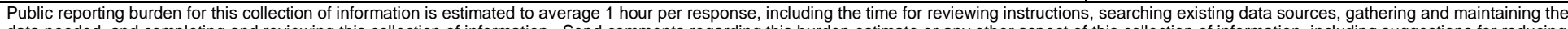

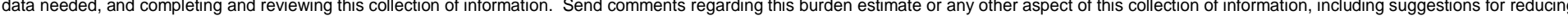

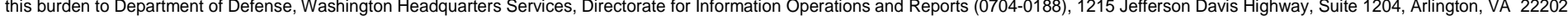

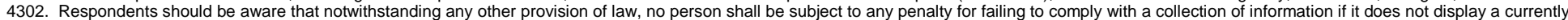
valid OMB control number. PLEASE DO NOT RETURN YOUR FORM TO THE ABOVE ADDRESS.

\begin{tabular}{l|l} 
1. REPORT DATE $(D D-M M-Y Y Y Y)$ & 2. REPORT TYPE
\end{tabular}

25-06-2014

Technical Paper

4. TITLE AND SUBTITLE

iNET Preamble Detector Performance in the Presence of Multipath Interference

Andrew McMurdie, Michael Rice, Erik Perrins

3. DATES COVERED (From - To)

5a. CONTRACT NUMBER:

W900KK-13-C-0026

5b. GRANT NUMBER: NIA

5c. PROGRAM ELEMENT NUMBER

5d. PROJECT NUMBER

5e. TASK NUMBER

5f. WORK UNIT NUMBER

7. PERFORMING ORGANIZATION NAME(S) AND ADDRESS(ES)

Department of Electrical \& Computer Engineering, 459 Clyde Building

Brigham Young University, Provo, UT 84602

8. PERFORMING ORGANIZATION REPORT NUMBER

412TW-PA-14319

University Of Kansas Center For Research, 2385 Irving Hill RD, Lawrence KS 66045-7563

9. SPONSORING I MONITORING AGENCY NAME(S) AND ADDRESS(ES)

Test Resource Management Center

Test and Evaluation/ Science and Technology

4800 Mark Center Drive, Suite 07J22, Alexandria, VA 22350

10. SPONSOR/MONITOR'S ACRONYM(S)

$\mathrm{N} / \mathrm{A}$

12. DISTRIBUTION I AVAILABILITY STATEMENT

Approved for public release A: distribution is unlimited.

\section{SUPPLEMENTARY NOTES}

CA: Air Force Flight Test Center Edwards AFB CA CC: 012100

\section{ABSTRACT}

Multiple preamble detectors are presented and applied to an SOQPSK-TG modulated signal in simulation. Multipath interference, additive white Gaussian noise, and frequency offsets are applied to the signal before detection is attempted. Simulation results are compared. A noncoherent post-detection integration (NCPDI) detector considered in this paper demonstrates the best detection performance for a reduced complexity.

\section{SUBJECT TERMS}

Preamble-Assisted Equalization for Aeronautical Telemtry (PAQ), Spectrum, Aeronautical telemetry, algorithm, bandwidth, Integrated Networked Enhanced Telemetry (iNET), Shaped Offset Quadrature Phase Shift Keying Test Group (SOQPSK-TG), bit error rate (BER), Orthogonal Frequency Division Multiplexing (OFDM), non-coherent post-detection integration (NCPDI)

\begin{tabular}{|c|c|c|c|c|c|}
\hline \multicolumn{3}{|c|}{$\begin{array}{l}\text { 16. SECURITY CLASSIFICATION OF: } \\
\text { Unclassified }\end{array}$} & \multirow{2}{*}{$\begin{array}{c}\text { 17. LIMITATION } \\
\text { OF ABSTRACT } \\
\text { None }\end{array}$} & \multirow{2}{*}{$\begin{array}{l}\text { 18. NUMBER } \\
\text { OF PAGES } \\
10\end{array}$} & $\begin{array}{l}\text { 19a. NAME OF RESPONSIBLE PERSON } \\
412 \text { TENG/EN (Tech Pubs) }\end{array}$ \\
\hline $\begin{array}{l}\text { a. REPORT } \\
\text { Unclassified }\end{array}$ & $\begin{array}{l}\text { b. ABSTRACT } \\
\text { Unclassified }\end{array}$ & $\begin{array}{l}\text { c. THIS PAGE } \\
\text { Unclassified }\end{array}$ & & & $\begin{array}{l}\begin{array}{l}\text { 19b. TELEPHONE NUMBER (include area } \\
\text { code) } \\
661-277-8615\end{array} \\
\end{array}$ \\
\hline
\end{tabular}




\title{
INET PREAMBLE DETECTOR PERFORMANCE IN THE PRESENCE OF MULTIPATH INTERFERENCE
}

\author{
Andrew McMurdie \\ Brigham Young University \\ Michael Rice \\ Faculty Advisor \\ Brigham Young University \\ Eric Perrins \\ University of Kansas
}

\begin{abstract}
Multiple preamble detectors are presented and applied to an SOQPSK-TG modulated signal in simulation. Multipath interference, additive white Gaussian noise, and frequency offsets are applied to the signal before detection is attempted. Simulation results are compared. A non-coherent post-detection integration (NCPDI) detector considered in this paper demonstrates the best detection performance for a reduced complexity.
\end{abstract}

\section{INTRODUCTION}

This paper will consider data-aided synchronization and equalization for aeronautical telemetry. The integrated Network Enhanced Telemetry (iNet) standard [1] describes a packet-based mode of data transfer, useful for telemetry downlinks. The standard defines each packet as consisting of three fields: a preamble, an attached sync marker (ASM), and data bits in the form of an LDPC codeword.

Data-aided synchronizers and equalizers operate by comparing a copy of a preamble (a known sequence) to the received copy. The frequency, phase, and timing offset can be estimated in the synchronizer. Previous work on this idea using iNET formatted SOQPSK-TG is shown in [2]. The comparison is used in the equalizer to estimate the impulse response of the channel in discrete time, which is then used to compute the optimum equalizer coefficients. See [3] for a more detailed example of this. 
The first challenge in either operation lies in determining the starting location of the preamble for each packet within the received signal. Whatever detector is employed to find the preamble must be robust enough to detect it reliably given unknown channels and frequency offsets. The detected preamble can then be used in the synchronizers or equalizers.

This paper will focus on preamble detection in SOQPSK-TG modulated data streams in the iNET format.

\section{SIGNAL MODEL}

The transmitted signal, $s(t)$, uses an SOQPSK-TG modulated carrier. Details on SOQPSK-TG are shown in [4] and [5]. Post-modulation, the signal is convolved with a frequency selective channel. In addition, a frequency offset and additive white Gaussian noise is added. The received signal is of the form

$$
r[n]=\left[\sum_{-N_{1}}^{N_{2}} h[k] s[n-k]\right] e^{j \omega_{0} n}+w[n]
$$

where $h[n]$ is the impulse response of the unknown channel with support on $-N_{1} \leq n \leq N_{2}, s[n]$ are the received samples of the SOQPSK-TG signal, $\omega_{0}$ is the unknown frequency offset, and $w[n]$ are samples of a zero-mean complex-valued white Gaussian noise process.

The bit pattern of the preamble must also be considered and chosen. From analysis in [6], the chosen sequence is CD98HEX repeated eight times. This pattern was chosen because the repetition allowed fast acquisition in burst-mode transmissions.

\section{THE MAXIMUM LIKELIHOOD PREAMBLE DETECTOR}

Barker [7] showed that preamble detection (also called "frame synchronization") was possible by maximizing a simple correlation function. Massey expounded on this by deriving the maximum likelihood (ML) preamble detector searching for binary data in Gaussian noise [8]. Gansman et al. addressed unknown carrier frequency and phase in the received signal [9]. Choi and Lee, who derived several ML functions examined in this paper, developed an ML detector that has a "double correlation" structure [10]. The Choi and Lee functions provide better performance over a wider frequency offset than the Gansman preamble detector [9].

Pedone et al. [11] showed a preamble detector from a series of balanced generalized post detection integration (B-GPDI) operations. Their work used a non-coherent combination of coherent partial correlations (also called "integrations"). This paper will utilize this structure, called noncoherent post detection integration (NCPDI) to derive two lower-complexity preamble detectors to be examined. 


\section{SIMPLE PREAMBLE DETECTOR}

The basic preamble detector structure in the literature consists of a correlation function that compares a known and stored copy of the preamble to the received samples. For this paper, let $p[n]$, $0 \leq n<L_{p}$ be the stored copy of the preamble of length $L_{p}-1$. In the AWGN case (where no frequency-selective channel or frequency offset is applied), the received signal takes the form $r[n]=s[n]+w[n]$. The correlation function is calculated as

$$
L_{0}[u]=\left|\sum_{n=u}^{u+L_{p}-1} r[n] p^{*}[n-u]\right|
$$

This function is evaluated once for each received sample. Over each packet length, the maximum value of $L_{0}$, called $i_{\text {max }}$, is chosen as the starting location of the preamble. If the true location of the preamble for a given packet is at sample $i$, then the preamble detector has correctly decided the starting location of the preamble if $i_{\max }=i$.

This detector has the advantage of being moderately simple in complexity. It required $4 L_{p}+2$ real-valued multiplications and a single square root operation.

\section{CHOI-LEE PREAMBLE DETECTORS}

In real telemetry, assuming an AWGN environment is inadequate to achieve good performance. The added interference of the frequency offset causes the simple preamble detector in (2) to fail; the frequency offset introduces destructive cancellation in the summation.

The Choi and Lee described "double correlation" functions exhibit good performance despite unknown channel and frequency offset.

The first function (called $L_{1}(u)$ in [10]) has the form

$$
L_{\mathrm{CL}-1 \mathrm{a}}[u]=\sum_{i=1}^{L_{p}-1}\left\{\left|\sum_{k=i}^{L_{p}-1} r^{*}[u+k] p[k] r[u+k-i] p^{*}[k-i]\right|-\sum_{k=u+i}^{u+L_{p}-1}|r[k]||r[k-i]|\right\}
$$

This function is computationally complex. It requires $\frac{1}{2}\left[13 L_{p}\left(L_{p}-1\right)+4 L_{p}\right]$ real-valued multiplications and $2 L_{p}-1$ square root operations for each index $u$.

If unknown frequency-selective multipath interference is also applied to the transmitted signal, the correction term in (3) can be omitted, resulting in the second Choi-Lee detector function:

$$
L_{\mathrm{CL}-1 \mathrm{~b}}[u]=\sum_{i=1}^{L_{p}-1}\left\{\left|\sum_{k=i}^{L_{p}-1} r^{*}[u+k] p[k] r[u+k-i] p^{*}[k-i]\right|\right\}
$$


This function needs only $6 L_{p}\left(L_{p}-1\right)$ real-valued multiplications, and $L_{p}-1$ square root operations.

Choi and Lee proposed two other functions that result from using only the $i=1$ terms in (3) and (4) to produce, respectively:

$$
L_{\mathrm{CL}-2}[u]=\left|\sum_{k=1}^{L_{p}-1} r^{*}[u+k] p[k] r[u+k-1] p^{*}[k-1]\right|-\sum_{k=u+1}^{u+L_{p}-1}|r[k]||r[k-1]|
$$

and

$$
L_{\mathrm{CL}-3}[u]=\left|\sum_{k=1}^{L_{p}-1} r^{*}[u+k] p[k] r[u+k-1] p^{*}[k-1]\right|
$$

The $L_{\mathrm{CL}-2}$ function requires $15 L_{p}-13$ real-valued multiplications and $L_{p}+1$ square root operations for each index $u$. The $L_{\mathrm{CL}-3}$ function requires $12\left(L_{p}-1\right)$ real-valued multiplications and a single square root operation for each index $u$.

For all of these functions, as in the AWGN case, the maximum value is found over the length of a packet. This is the decided location of the preamble.

\section{NCPDI PREAMBLE DETECTORS}

An inherent disadvantage of the Choi and Lee detectors is the overwhelming computational complexity required for each sample value $u$. Running these detectors in real-time is a difficult proposition at best; it is desirable to find a reduced-complexity detector that will achieve good performance even in unknown multipath interference and frequency offset environments.

We adapt the non-coherent post-detection integration (NCPDI) detector developed in [11]. We first write the correlation interval as $L_{p}=L_{\mathrm{PDI}} L_{\text {coh }}$ to separate the correlation into two sections: coherent correlations of length $L_{\mathrm{coh}}$, and $L_{\mathrm{PDI}}$ non-coherent sums of the $L_{\mathrm{coh}}$ combinations. This is written as

$$
L_{\mathrm{NCPDI}}[u]=\sum_{k=0}^{L_{\mathrm{PDI}}-1}\left|\sum_{m=k L_{\mathrm{coh}}}^{(k+1) L_{\mathrm{coh}}-1} r[u+m] p^{*}[m]\right|^{2}
$$

Taking advantage of the chosen preamble structure, we set $L_{\mathrm{coh}}=32$. This is the length of the repeating sequence in the preamble (at 2 samples per bit). Choosing this value then forces $L_{\mathrm{PDI}}=$ 8. Further taking advantage of the fact that $p[n]$ is the form of the modulated bit pattern repeated eight times, let $q[n]$ be the SOQPSK-TG modulated samples of a single repeating section of the preamble (corresponding to the bits CD98HEX), with length $L_{q}$. With some variable manipulation, we can write the function as 


$$
L_{\mathrm{NCPDI}-1}[u]=\sum_{k=0}^{7}\left|\sum_{l=0}^{L_{q}-1} r\left[u+k L_{q}+l\right] q^{*}[l]\right|^{2}
$$

This function requires $4 L_{q}+16$ real-valued multiplications and zero square root operations for each index $u$.

A simplified version of this detector quantizes the possible values of $q[n]$ to $\pm 1, \pm j$, and $\frac{1}{\sqrt{2}}( \pm 1 \pm$ $j$ ). This function, denoted $L_{\mathrm{NCPDI}-2}$, requires only 32 real-valued multiplications and zero square root operations for each index $u$.

\section{PERFORMANCE}

At $N=2$ samples per bit and using the preamble structure shown above, Table 1 lists the proposed functions and their computational requirements for each index $u$. As was desired, the NCPDI detectors have a significantly reduced computational complexity.

Table 1: Computational Complexity of the Candidate Preamble Detectors

For a Sample Rate of $N=2$ Samples/Bit

\begin{tabular}{|l|r|r|}
\hline $\mathbf{L}[\mathbf{u}]$ & \# Real-Value Mults. & \# Square-Roots \\
\hline$L_{0}[u]$ & 1,026 & 1 \\
\hline$L_{\mathrm{CL}-1 \mathrm{a}}[u]$ & 424,832 & 511 \\
\hline$L_{\mathrm{CL}-1 \mathrm{~b}}[u]$ & 391,680 & 255 \\
\hline$L_{\mathrm{CL}-2}[u]$ & 3,827 & 257 \\
\hline$L_{\mathrm{CL}-3}[u]$ & 3,060 & 1 \\
\hline$L_{\mathrm{NCPDI}-1}[u]$ & 1,040 & 0 \\
\hline$L_{\mathrm{NCPDI}-2}[u]$ & 32 & 0 \\
\hline
\end{tabular}

All of these functions were tested in simulation, and performance was gauged by the mean and variance of $i-i_{\max }$. Simulations were performed with three different channel impulse responses, all of which were captured during channel sounding experiments at Edwards AFB, California [12]. See Figure 1 for the frequency responses of the channels. The simulations were run with a bit rate of $10.3125 \mathrm{Mbits} / \mathrm{s}$, using SOQPSK-TG modulation at a sample rate of $N=2$ two samples/bit. Frequency offsets of $\Delta f=0 \mathrm{~Hz}$ and $\Delta f=50 \mathrm{KHz}$ were applied.

As shown in figures $2 \mathrm{a}-2 \mathrm{f}$, the detectors using $L_{\mathrm{CL}-1 \mathrm{a}}, L_{\mathrm{CL}-1 \mathrm{~b}}, L_{\mathrm{NCPDI}-1}$ and $L_{\mathrm{NCPDI}-2}$ exhibited great performance in all test scenarios. The mean error for the detectors using these functions was very nearly zero, even in the high frequency offset environments.

Some caution must be exercised when examining the variance results. Because many of the index errors were zero the number of errors from which the variance estimate is determined is small, 
causing the estimate to be somewhat unreliable. This is especially true for the $L_{\mathrm{CL}-1 \mathrm{a}}$ and $L_{\mathrm{CL}-1 \mathrm{~b}}$ based detectors, who had nearly zero errors across the board.

However, we can draw general conclusions from the results. The $L_{\mathrm{CL}-1 \mathrm{a}}$ and $L_{\mathrm{CL}-1 \mathrm{~b}}$ based detectors had the best performance, followed closely by the $L_{\mathrm{NCPDI}-1}$ and $L_{\mathrm{NCPDI}-2}$ based detectors. The $L_{\mathrm{CL}-2}$ and $L_{\mathrm{CL}-3}$ detectors came third in performance, although their error variances were quite different from channel to channel.

The correction term found in in $L_{\mathrm{NCPDI}-1}$ and $L_{\mathrm{CL}-2}$ had a curious effect on the detector performance. Depending on the channel, it either improved or degraded system performance when compared to the $L_{\mathrm{CL}-1 \mathrm{~b}}$ and $L_{\mathrm{CL}-3}$ detector systems. It appears that the varying ISI from channel to channel coupled with the correction term causes detector performance to vary, as well.

As expected, the simple detector based on $L_{0}$ showed good performance when the frequency offset $\Delta f=0 \mathrm{~Hz}$, but had terrible performance when the frequency offset $\Delta f=50 \mathrm{KHz}$.

\section{CONCLUSIONS}

We have shown that of the candidate functions listed, the reduced complexity NCPDI detector provides the best tradeoff between performance and computational complexity. It is also shown that preamble detectors based on SOQPSK-TG samples can have good performance, despite an unknown frequency offset and unknown ISI.

\section{ACKNOWLEDGMENTS}

This work was funded by the Test Resource Management Center (TRMC) Test and Evaluation Science and Technology (T\&E/S\&T) Program through the U.S. Army Program Executive Office for Simulation, Training and Instrumentation (PEO STRI) under contract W900KK-13-C-0026 (PAQ).

\section{REFERENCES}

[1] integrated Network Enhanced Telemetry (iNET) Radio Access Network Standards Working Group, "Radio access network (ran) standard, version 0.7.9." [Online]. Available: https://www.tena-sda.org/display/INET/iNET+Platform+Interface+Standards

[2] M. Rice and E. Perrins, "On frequency offset estimation using the iNET preamble in frequency selective fading channels," submitted to the 2014 IEEE Military Communications Conference. 
[3] M. Rice, M. S. Afran, M. Saquib, A. Cole-Rhodes, and F. Moazzami, "On the performance of equalization techniques for aeronautical telemetry," submitted to IEEE Transactions on Aerospace \& Electronic Systems, 2014.

[4] E. Perrins and M. Rice, "Reduced-complexity approach to iterative detection of coded SOQPSK,” IEEE Transactions on Communications, vol. 55, no. 7, pp. 1354-1362, July 2007.

[5] T. Nelson, E. Perrins, and M. Rice, "Near optimal common detection techniques for shaped offset QPSK and Fehers QPSK," IEEE Transactions on Communications, vol. 56, no. 5, pp. 724-735, May 2008.

[6] B. Erkmen, A. Tkacenko, and C. Okino, "Preamble design for symbol timing estimation from SOQPSK-TG waveforms," Proceedings of the International Telemetering Conference, October 2009.

[7] R. Barker, Group synchronization of binary digital systems. London: Butterworth, 1953.

[8] J. Massey, “Optimum frame synchronization," IEEE Transactions on Communications, vol. 20, no. 2, pp. 115-119, April 1972.

[9] J. Gansman, M. Fitz, and J. Krogmeier, "Optimum and suboptimum frame synchronization for pilot-symbol-assisted modulation," IEEE Transactions on Communications, vol. 45, no. 10, pp. 1327-1337, October 1997.

[10] Z. Choi and Y. Lee, "Frame synchronization in the presence of frequency offset," IEEE Transactions on Communications, vol. 50, no. 7, pp. 1062-1065, July 2002.

[11] R. Pedone, M. Villanti, A. Vanelli-Coralli, G. Corazza, and P. Mathiopoulos, "Frame synchronization in frequency uncertainty," IEEE Transactions on Communications, vol. 58, no. 4, pp. 1235-1246, April 2010.

[12] M. Rice and M. Jensen, "A comparison of L-band and C-band multipath propagation at Edwards AFB," Proceedings of the International Telemetering Conference, October 2011. 

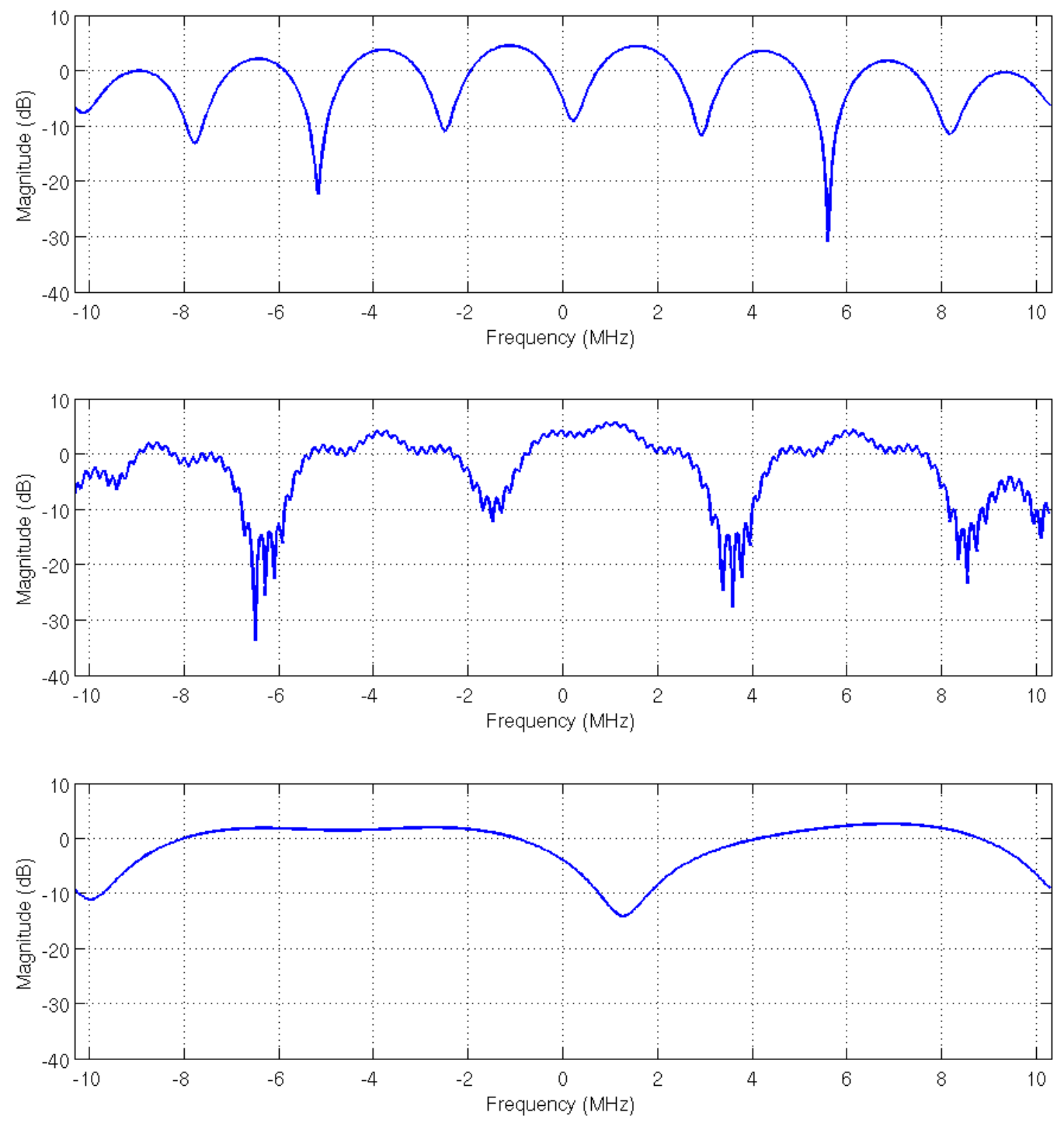

Figure 1: The example channels from channel sounding experiments at Edwards AFB: (top) a length-9 channel from the flight line; (middle) a length-19 channel from take-off; (bottom) a length-5 channel from low-elevation angle "up and away" flight. 


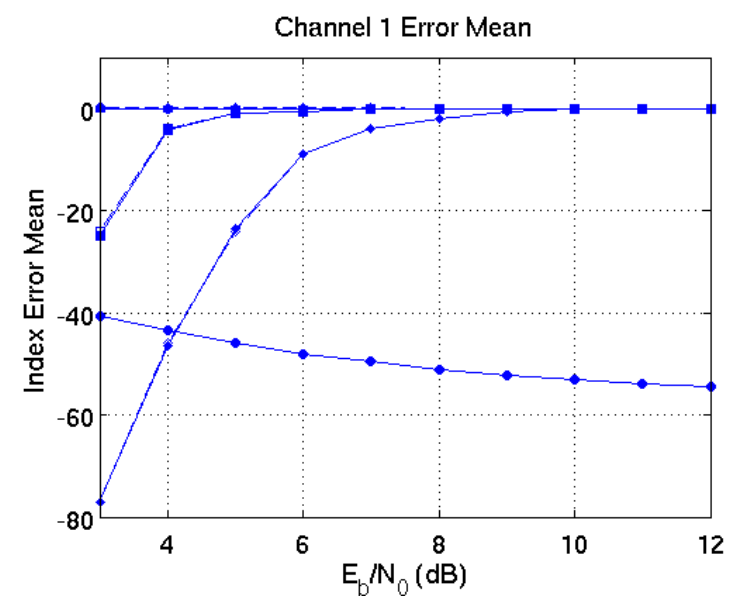

(a) Error means for simulations with channel 1

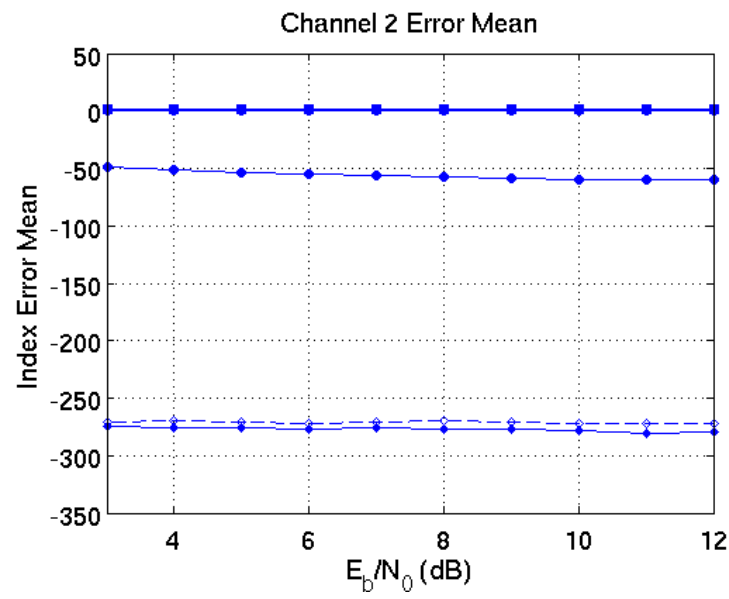

(c) Error means for simulations with channel 2

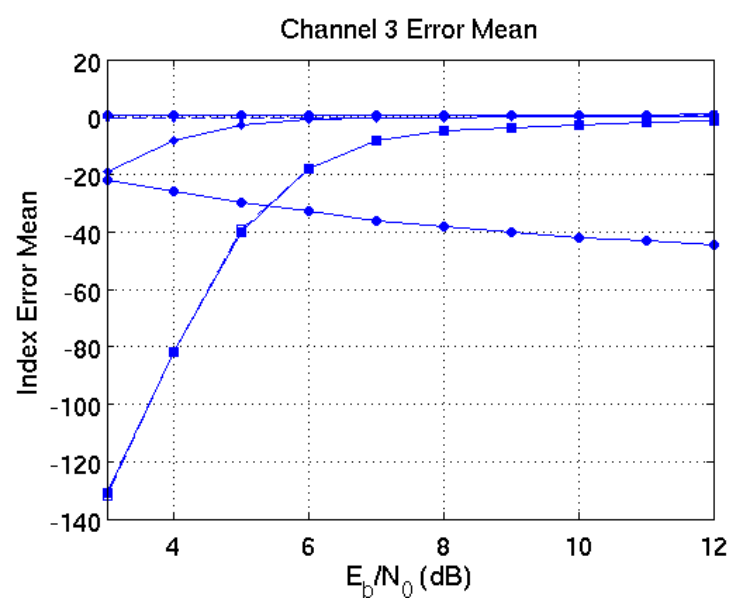

(e) Error means for simulations with channel 3

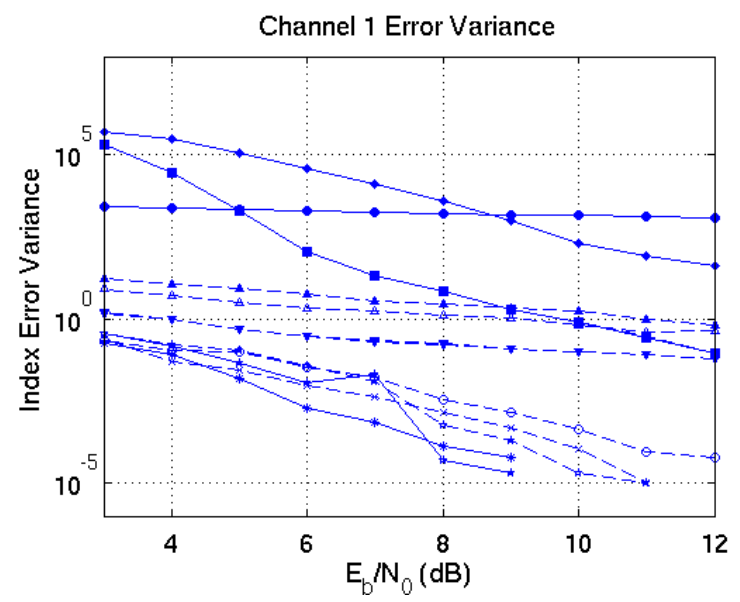

(b) Error variances for simulations with channel 1

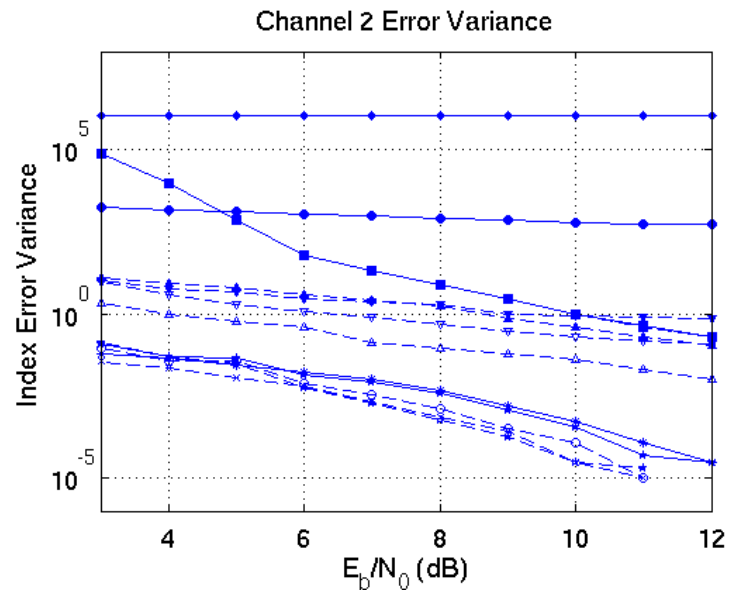

(d) Error variances for simulations with channel 2

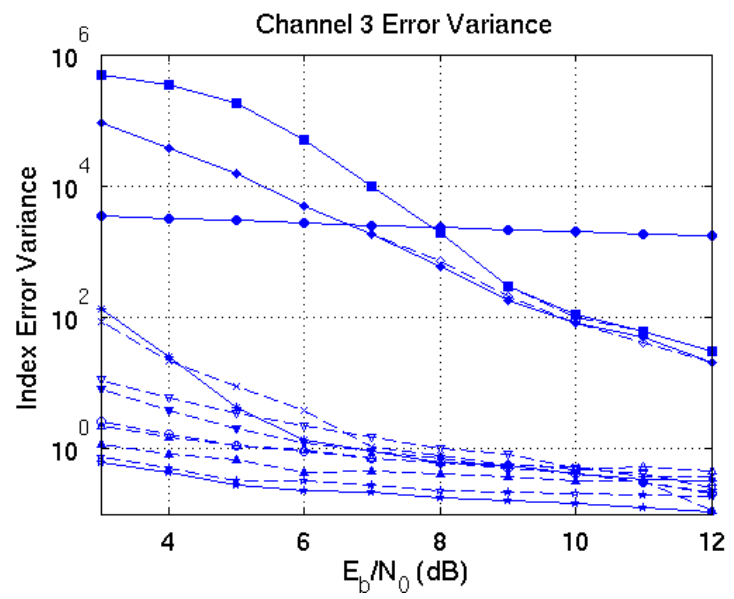

(f) Error variances for simulations with channel 3

Figure 2: All simulation results. See figure 3 for plot legend. 


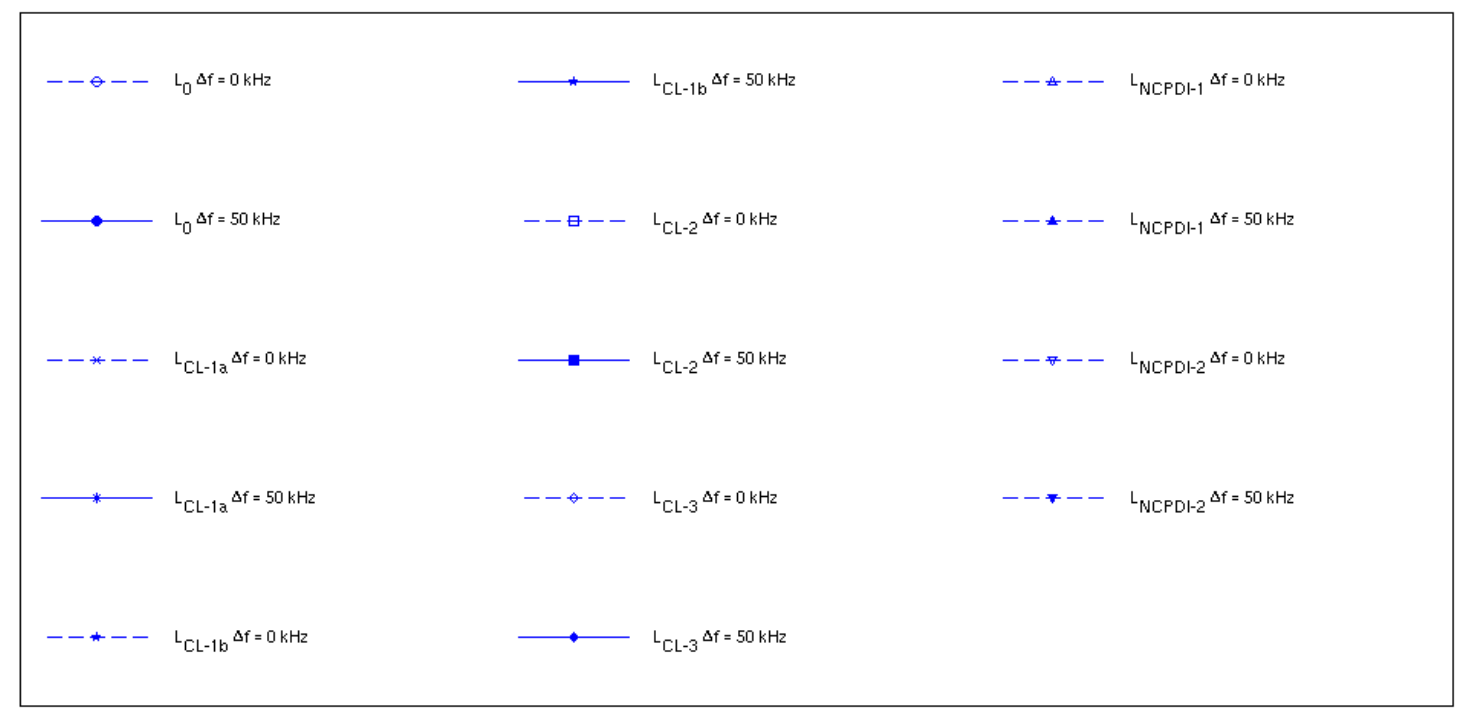

Figure 3: Plot legend for figures $2 \mathrm{a}-2 \mathrm{f}$. 